\title{
Clinical Features and Outcomes of Very Elderly Patients Admitted to the Intensive Care Unit: A Retrospective and Observational Study
}

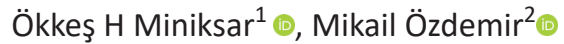

\begin{abstract}
Background: In this study, we aim to describe clinical features and outcomes of very elderly (85 years old or older) patients and provide information about predictors of mortality and factors associated with the length of hospital stay (LOS).

Materials and methods: We reviewed retrospectively the files of patients over 85 years old and older who were admitted to the intensive care unit (ICU) of our training and research hospital between January 2017 and December 2018. Demographic and clinical findings, treatment modalities, and outcomes were recorded. The patients who died during the ICU stay were compared to the survivors, and factors associated with mortality and LOS in the intensive care were evaluated.

Results: We reviewed 2350 files, and 218 patients (58.3\% females) were included. The rate of mortality was $81.7 \%$. The factors independently associated with a higher rate of mortality were the acute physiology and chronic health evaluation (APACHE) II score; the need for mechanical ventilation (MV), or inotropic support; and the presence of coronary artery disease (CAD) or chronic kidney disease (CKD). A tracheostomy and a blood transfusion were inversely associated with mortality. We found an association between LOS and comorbidities (renal replacement, percutaneous gastrostomy, blood transfusion, and a tracheostomy).

Conclusion: The rate of survival in the intensive care was low among these very elderly intensive care patients. A higher APACHE II score; application of MV or inotropic support; and the presence of CAD or CKD were associated with a higher mortality rate.

Keywords: Geriatrics, Intensive care, Mortality.

Indian Journal of Critical Care Medicine (2021): 10.5005/jp-journals-10071-23846
\end{abstract}

\section{INTRODUCTION}

The elderly people constitute nearly $9.1 \%$ of the world population (2019), and the proportion of individuals over the age of 80 is estimated to triple by the year 2050. ${ }^{1}$ In Turkey, the proportion of adults at the age of 65 or older constitutes $8.8 \%$ of the population, and this is estimated to increase to $12.9 \%$ by $2030 .^{2}$ Individuals at the age of 85 or older (very elderly people) are estimated to have the highest rate of increase compared to previous years. ${ }^{2}$

As the rate increases for the older adult population, more elderly people with multiple comorbidities are admitted to the intensive care units (ICUs). ${ }^{3}$ Patients over 65,80 , and 85 years old constitute $50 \%, 10 \%$, and $5-6 \%$ of ICU admissions, respectively. ${ }^{4}$ These rates vary in each country and with respect to characteristics of ICUs. ${ }^{4}$ The standards for admitting very elderly patients with short-life expectancies to ICUs are controversial because of the limited number of ICU beds and resources, high costs, and negative outcomes. ${ }^{4,5}$

Most of the studies regarding the outcomes of very elderly patients in ICUs reported that survival rates are low and quality of life is poor in survivors. ${ }^{6}$ Apart from old age, significant contributors to negative outcomes include functional incapacity, frailty, primary diagnosis, and comorbidities. ${ }^{4,6,7}$ While the outcomes of older adult patients have been extensively investigated in Turkey, studies regarding the outcomes of very old patients are rather scarce.

The primary goal of this study is to investigate predictors of mortality in very old patients in the general ICU of a tertiary hospital in Turkey. The secondary goal is to define clinical features and predictors of length of hospital stay (LOS) in these patients.
${ }^{1}$ Faculty of Medicine, Department of Anesthesiology and Reanimation, Yozgat Bozok University, Yozgat, Turkey

${ }^{2}$ Public Health Department, Tuberculosis Dispensary, Osmaniye Community Health Center, Osmaniye, Turkey

Corresponding Author: Ökkeş H Miniksar, Faculty of Medicine, Department of Anesthesiology and Reanimation, Yozgat Bozok University, Yozgat, Turkey, Phone:+90 354 2127060, e-mail: hminiksar@ yahoo.com

How to cite this article: Miniksar OH, Özdemir M. Clinical Features and Outcomes of Very Elderly Patients Admitted to the Intensive Care Unit: A Retrospective and Observational Study. Indian J Crit Care Med 2021; 25(6):629-634.

Source of support: Nil

Conflict of interest: None

\section{Materials and Methods}

We conducted the study at the Training and Research Hospital, which has 1460 beds and admits more than 80,000 patients annually. We performed the study between January 2017 and December 2018 in the ICU of our hospital (36 beds and nearly 2350 annual admissions). The study took place in an ICU that admitted adult surgical and medical patients, and we reviewed retrospectively the files of very elderly patients. We excluded those who were discharged on patient demand before the end of the treatment, referred to other hospitals, or in whom study

(-) Jaypee Brothers Medical Publishers. 2021 Open Access This article is distributed under the terms of the Creative Commons Attribution 4.0 International License (https://creativecommons.org/licenses/by-nc/4.0/), which permits unrestricted use, distribution, and non-commercial reproduction in any medium, provided you give appropriate credit to the original author(s) and the source, provide a link to the Creative Commons license, and indicate if changes were made. The Creative Commons Public Domain Dedication waiver (http://creativecommons.org/publicdomain/zero/1.0/) applies to the data made available in this article, unless otherwise stated. 
variables were missing. If the index patient had more than one admission during the study period, only the first admission was included. We recorded demographic data, referring unit, patient type (surgical/medical), LOS, comorbidities, length of mechanical ventilation (MV), hemodialysis treatment, blood transfusions, need for inotropic support, and tracheostomy and percutaneous endoscopic gastrostomy (PEG) interventions. Surgical ICU patients were defined as those who underwent surgery after admission to the hospital. Patients who needed MV were defined as those who underwent resuscitation and endotracheal intubation for cardiac or respiratory arrest. We also recorded acute physiology and chronic health evaluation (APACHE) II scores on admission and albumin and lactate levels. The data were extracted from the patient files and the hospital information management system. The patients were evaluated in two groups: survivors (those discharged to home or transferred to other wards) and nonsurvivors (those dead during ICU admission). We examined the relationship between the procedures applied in the ICU and LOS. The study protocol was approved by the local ethical committee (Ethical Committee approval number 2019/140).

\section{Statistical Analysis}

Statistical analyses were performed by a biostatistician using SPSS Statistics version 17.0 (IBM). The normality of data was analyzed by using Kolmogorov-Smirnov test. The descriptive statistics were reported in mean \pm standard deviation, medians, and ranges (min-max). Mann-Whitney $U$ test and KruskalWallis test are used to see whether there are average difference between the unrelated groups, accordingly binominal and multinominal variables. OS analyses of the groups were evaluated with Kaplan-Meier curves, and differences were tested with a log-rank test and Cox regression analysis. All comparative tests were 2-tailed, and a $p$ value of less than 0.05 was considered to be statistically significant.

\section{Results}

We reviewed retrospectively 256 patient files. Among these, 10 were discharged on patient demand, three were referred to other units before the end of ICU treatment, 15 had missing data (clinical data, 6; laboratory data, 4; admission diagnosis, 3; mortality scoring, 2; laboratory data and mortality scoring, 4), and 10 had more than one admission. The remaining 218 patients were included in the study (Flowchart 1).

The majority of the patients $(n=127)(58.3 \%)$ were female, and $155(71.1 \%)$ of them were referred by the emergency services of MTRH to ICU. Table 1 lists the baseline characteristics of the study population. The ages of the study population ranged from 85 to 103, and their APACHE II scores ranged from 8 to 49.

When the primary diagnoses of admission to ICU were examined, it was found that mortality was significantly higher in patients who needed MV ( $p=0.001)$. Intoxication, other medical diseases, and surgery were related to ICU survival. However, the number of these variables is very small, and they could not be analyzed with the regression analysis.

The results of the Cox regression analysis are presented in Table 2. In univariate analyses, the APACHE II score was associated with mortality. Also, MV, some comorbidities (neurologic disease, coronary artery disease [CAD], and chronic kidney disease [CKD]), tracheostomy, PEG, blood transfusion, and the need for inotropic support were associated with mortality. These nine variables were included in the multivariate Cox regression analysis (Table 2). APACHE II score, MV, CAD, CKD, tracheostomy, blood transfusion, and the need for inotropic support were independently associated with mortality. The variables associated with LOS are shown in Table 3.

Flowchart 1: Retrospective study patient inclusion procedure (study flow diagram)

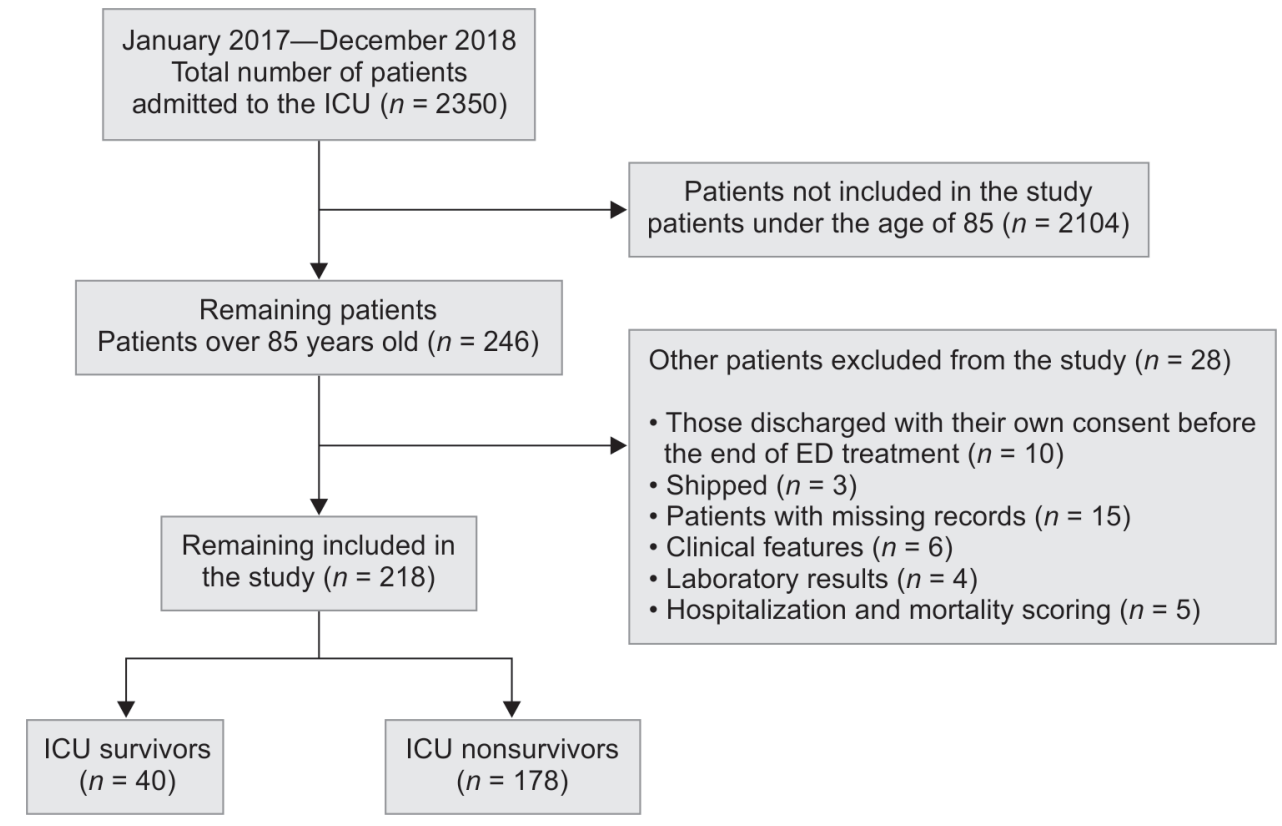


Table 1: Patient characteristics

\begin{tabular}{|c|c|c|c|c|c|c|c|c|}
\hline \multirow{2}{*}{$\begin{array}{l}\text { Patient characteristics } \\
\text { Gender }\end{array}$} & \multirow[b]{2}{*}{ Male } & \multicolumn{2}{|c|}{ ICU survivors $(n=40)$} & \multicolumn{2}{|c|}{$\begin{array}{l}\text { ICU nonsurvivors } \\
(n=178)\end{array}$} & \multicolumn{2}{|c|}{ All patients $(n=218)$} & \multirow{2}{*}{$\frac{p \text { value }}{0.096^{*}}$} \\
\hline & & 12 & $13.2 \%$ & 79 & $86.8 \%$ & 91 & $41.7 \%$ & \\
\hline & Female & 28 & $22.0 \%$ & 99 & $78.0 \%$ & 127 & $58.3 \%$ & \\
\hline Age (years) & & 89.0 & $85.5-92.0$ & 87.0 & $86.0-90.0$ & 87.0 & $86.0-90.0$ & $0.545 \neq$ \\
\hline \multirow[t]{2}{*}{ Patient type } & Medical & 29 & $15.7 \%$ & 156 & $84.3 \%$ & 185 & $84.9 \%$ & $0.016^{*}$ \\
\hline & Surgical & 11 & $33.3 \%$ & 22 & $66.7 \%$ & 33 & $15.1 \%$ & \\
\hline \multirow[t]{4}{*}{ Referring unit } & Emergency service & 38 & $24.5 \%$ & 117 & $75.5 \%$ & 155 & $71.1 \%$ & $0.008+$ \\
\hline & Palliative care unit & 0 & $0.0 \%$ & 6 & $100.0 \%$ & 6 & $2.8 \%$ & \\
\hline & Wards & 1 & $4.0 \%$ & 24 & $96.0 \%$ & 25 & $11.5 \%$ & \\
\hline & Other ICU & 1 & $3.1 \%$ & 31 & $96.9 \%$ & 32 & $14.7 \%$ & \\
\hline \multirow{12}{*}{$\begin{array}{l}\text { Admission } \\
\text { diagnosis }\end{array}$} & Sepsis & 9 & $20.9 \%$ & 34 & $79.1 \%$ & 43 & $19.7 \%$ & 0.626 \\
\hline & Respiratory disease & 4 & $16.0 \%$ & 21 & $84.0 \%$ & 25 & $11.5 \%$ & 0.747 \\
\hline & Need for MV & 4 & $5.9 \%$ & 64 & $94.1 \%$ & 68 & $31.2 \%$ & 0.001 \\
\hline & Heart disease & 0 & $0.0 \%$ & 3 & $100.0 \%$ & 3 & $1.4 \%$ & 0.409 \\
\hline & Neurologic disease & 5 & $22.7 \%$ & 17 & $77.3 \%$ & 22 & $10.1 \%$ & 0.561 \\
\hline & $\begin{array}{l}\text { Cerebral } \\
\text { hemorrhage }\end{array}$ & 0 & $0.0 \%$ & 14 & $100.0 \%$ & 14 & $6.4 \%$ & 0.284 \\
\hline & Acute kidney injury & 1 & $8.3 \%$ & 11 & $91.7 \%$ & 12 & $5.5 \%$ & 0.357 \\
\hline & Trauma & 0 & $0.0 \%$ & 5 & $100.0 \%$ & 5 & $2.3 \%$ & 0.233 \\
\hline & Abdominal surgery & 4 & $44.4 \%$ & 5 & $55.6 \%$ & 9 & $4.1 \%$ & 0.039 \\
\hline & Other surgery & 7 & $70.0 \%$ & 3 & $30.0 \%$ & 10 & $4.6 \%$ & $<0.001$ \\
\hline & Other medical disease & 2 & $100.0 \%$ & 0 & $0.0 \%$ & 2 & $0.9 \%$ & 0.002 \\
\hline & Intoxication & 4 & $80.0 \%$ & 1 & $20.0 \%$ & 5 & $2.3 \%$ & $<0.001$ \\
\hline \multirow[t]{7}{*}{ Comorbidities } & Hypertension & 25 & $25.5 \%$ & 73 & $74.5 \%$ & 98 & $45.0 \%$ & 0.013 \\
\hline & Heart failure & 11 & $19.0 \%$ & 47 & $81.0 \%$ & 58 & $26.6 \%$ & 0.827 \\
\hline & Diabetes mellitus & 5 & $14.7 \%$ & 29 & $85.3 \%$ & 34 & $15.6 \%$ & 0.551 \\
\hline & Neurologic disease & 15 & $23.1 \%$ & 50 & $76.9 \%$ & 65 & $29.8 \%$ & 0.240 \\
\hline & Coronary artery disease & 4 & $13.3 \%$ & 26 & $86.7 \%$ & 30 & $13.8 \%$ & 0.445 \\
\hline & Chronic kidney disease & 1 & $5.3 \%$ & 18 & $94.7 \%$ & 19 & $8.7 \%$ & 0.123 \\
\hline & Respiratory disease & 16 & $22.9 \%$ & 54 & $77.1 \%$ & 70 & $32.1 \%$ & 0.238 \\
\hline Length of stay (days) & & 7.0 & $4.0-10.5$ & 4.0 & $1.0-14.0$ & 5.0 & $1.0-13.0$ & $0.013 \neq$ \\
\hline APACHE II score & & 19.0 & $12.5-25.0$ & 29.0 & $23.0-36.0$ & 28.0 & $20.0-36.0$ & $<0.001 \neq$ \\
\hline Need for MV & & 8 & $4.4 \%$ & 172 & $95.6 \%$ & 180 & $82.6 \%$ & $<0.001^{*}$ \\
\hline Need for NIMV & & 13 & $41.9 \%$ & 18 & $58.1 \%$ & 31 & $14.2 \%$ & $<0.001^{*}$ \\
\hline Albumin level (g/dL) & & 3.3 & $2.7-3.8$ & 2.9 & $2.4-3.5$ & 3.0 & $2.5-3.6$ & $<0.001 \neq$ \\
\hline Lactate level (mEq/L) & & 2.2 & $1.6-2.5$ & 3.8 & $2.3-6.9$ & 3.3 & $2.0-6.4$ & $0.016 \neq$ \\
\hline
\end{tabular}

${ }^{*}$ Chi-square test; ${ }^{\ddagger}$ Mann-Whitney $\mathrm{U}$ test; ${ }^{\dagger}$ Fisher's exact test; MV, mechanical ventilation; NIMV, noninvasive mechanical ventilation; APACHE, acute physiology and chronic health evaluation; ICU, intensive care unit; CPR, cardiopulmonary resuscitation

\section{Discussion}

Although very elderly people are more commonly admitted to ICUs, there is a lack of information about their prognoses and outcomes. Several studies have investigated the outcomes of elderly patients in ICUs. In this study, we focused on very elderly patients, because this age segment of the population is the most rapidly growing one, ${ }^{1}$ the admission rate of these patients to ICUs has increased, and outcomes of treatment in an ICU are commonly poor. ${ }^{4} \mathrm{~A}$ controversy exists over whether these patients should be admitted to ICUs. ${ }^{4,8}$ In many countries, the capacity of health-care systems is at the risk of becoming overwhelmed because many very elderly patients receive end-of-life care in ICUs. ${ }^{8}$ For these reasons, caring for very elderly patients in ICUs is an emerging health-care problem in Turkey. Furthermore, when we consider the capacity of ICU beds and organization and COVID-19 pandemic process, the present study and similar ones have strategic importance.

Whereas age was reported as a prognostic factor in critical patients in some studies, ${ }^{4,9,10}$ other studies suggested that disease severity, admission diagnosis, and comorbidities were more important risk factors than age. ${ }^{4,6,7}$ It is also well known that very elderly patients are admitted to hospital wards more commonly 
Table 2: Factors affecting survival

\begin{tabular}{|c|c|c|c|c|c|c|c|c|}
\hline & \multirow[t]{2}{*}{$H . R}$. & \multicolumn{2}{|c|}{$95.0 \%$ Cl for H.R. } & \multirow{2}{*}{ p Value } & \multirow{2}{*}{$H . R}$. & \multicolumn{2}{|c|}{$95.0 \%$ Cl for H.R. } & \multirow{2}{*}{$p$ value } \\
\hline & & Lower & Upper & & & Lower & Upper & \\
\hline Male & 0.953 & 0.703 & 1.292 & 0.757 & 1.058 & 0.761 & 1.470 & 0.737 \\
\hline Age & 0.981 & 0.941 & 1.024 & 0.379 & 1.015 & 0.974 & 1.059 & 0.474 \\
\hline APACHE II score & 1.063 & 1.045 & 1.082 & $<0.001$ & 1.048 & 1.029 & 1.068 & $<0.001$ \\
\hline Need for MV & 5.097 & 2.248 & 11.557 & $<0.001$ & 3.316 & 1.400 & 7.854 & 0.006 \\
\hline Diabetes mellitus & 0.821 & 0.545 & 1.235 & 0.343 & & & & \\
\hline Neurologic disease & 1.734 & 1.227 & 2.450 & 0.002 & 1.106 & 0.768 & 1.592 & 0.589 \\
\hline Coronary artery disease & 1.698 & 1.112 & 2.592 & 0.014 & 1.634 & 1.053 & 2.536 & 0.028 \\
\hline Chronic kidney disease & 1.735 & 1.062 & 2.835 & 0.028 & 3.111 & 1.828 & 5.295 & $<0.001$ \\
\hline Respiratory disease & 0.823 & 0.597 & 1.136 & 0.236 & & & & \\
\hline Renal replacement therapy & 0.868 & 0.525 & 1.436 & 0.582 & & & & \\
\hline Tracheostomy & 0.097 & 0.042 & 0.223 & $<0.001$ & 0.112 & 0.040 & 0.314 & $<0.001$ \\
\hline PEG & 0.742 & 0.650 & 0.884 & $<0.001$ & 0.820 & 0.273 & 2.467 & 0.724 \\
\hline Blood transfusion & 0.227 & 0.156 & 0.332 & $<0.001$ & 0.256 & 0.170 & 0.385 & $<0.001$ \\
\hline Need for inotropic support & 1.861 & 1.028 & 3.368 & 0.040 & 1.946 & 1.030 & 3.677 & 0.040 \\
\hline
\end{tabular}

$\mathrm{MV}$, mechanical ventilation; $\mathrm{PEG}$, percutaneous endoscopic gastrostomy

Table 3: Association of LOS with study variables

\begin{tabular}{lccccc}
\hline & & \multicolumn{3}{c}{ Length of hospital stay } & \\
\cline { 3 - 5 } & & Median & Percentile 25 & Percentile 75 & \\
\hline All patients & 5.0 & 1.0 & 13.0 & N/A \\
Outcome & Dead & 4.0 & 1.0 & 14.0 & \\
& Transferred & 5.0 & 4.0 & 7.0 & $0.003^{\dagger}$ \\
& Discharged & 15.0 & 7.0 & 30.0 & \\
Two or more comorbidities & & 5.0 & 2.0 & 15.0 & 0.248 \\
Three or more comorbidities & 7.0 & 3.0 & 20.0 & $0.028^{*}$ \\
Hypertension & 5.0 & 2.0 & 14.0 & 0.614 \\
Coronary artery disease & 5.5 & 2.0 & 17.0 & 0.428 \\
Diabetes mellitus & 4.5 & 2.0 & 15.0 & 0.481 \\
Renal replacement & 9.5 & 4.0 & 29.0 & $0.024^{*}$ \\
Tracheostomy & 75.5 & 49.5 & 136.0 & $<0.001^{*}$ \\
PEG & 113.0 & 75.0 & 150.0 & $<0.001^{*}$ \\
Blood transfusion & 13.0 & 5.0 & 34.0 & $<0.001^{*}$ \\
Need for inotropic support & 5.0 & 1.0 & 15.0 & $0.639^{*}$ \\
\hline${ }^{\dagger}$ Kruskal-Wallis test: *Mann-Whitney U test: PEG, percutaneous endoscopic gastrostomy &
\end{tabular}

than younger ones and that they have a higher mortality rate. ${ }^{10}$ The proportion of very elderly patients who are transferred from emergency units to ICUs ranges from $7.9 \%$ to $21.7 \%$ in several studies. ${ }^{3,6,10,11}$ In this study, the rate was $9.14 \%$.

Several studies reported that among very elderly ICU patients, women have a better prognosis. ${ }^{6,7,12}$ Likely, in this study, the proportion of female patients was higher than males $(58.3 \%$ vs $41.7 \%$ ). Also, the mortality rate was lower, and the mean LOS was shorter in females. Reinikainen et al. ${ }^{12}$ reported that male gender was a poor prognostic factor in ICUs, and male patients used nearly two-thirds of ICU beds.

The prognosis of very elderly patients may vary with respect to whether the index case is a surgical or medical patient. The rate of mortality in ICU patients who underwent elective surgery is lower when compared with medical ICU patients. On the contrary, the rate of mortality in ICU patients who underwent unplanned surgery is higher as compared to medical ICU patients. ${ }^{6}$ In the present study, surgical patients had a significantly lower rate of mortality compared to medical patients.

The admission diagnosis has also been reported as an important prognostic factor. ${ }^{6,9,11,13,14}$ Cardiovascular, ${ }^{6}$ respiratory, ${ }_{1}^{13}$ gastrointestinal, ${ }^{14}$ infectious, and cerebrovascular diseases constitute the most common admission diagnoses. However, admission diagnoses may vary with respect to ICU type and index patient population. In the present study, the most common admission diagnoses were cardiac or respiratory arrest requiring 
MV. The patients who were admitted to ICU for these indications had a very high rate of mortality (94.1\%).

The presence of critical comorbidities and decrease in physiological reserves during the older age period negatively affect the prognosis in ICUs. ${ }^{4,6}$ In this study, almost all of the patients had at least one comorbidity. In line with the literature, the most common comorbidities were hypertension (48.1\%), respiratory diseases (32.5\%), and neurodegenerative diseases (29.8\%). ${ }^{14}$

It is important to determine factors related to mortality in very elderly ICU patients and develop management strategies for these patients in order to use ICUs wisely. In this study, the rate of mortality $(81.7 \%)$ was higher than that reported in other studies. We think that ICU type and the presence of terminal-stage-care patients underlie this high mortality rate. Furthermore, most of the patients $(71.1 \%)$ were transferred to the ICU from the emergency unit. Notably, almost all of the patients who were transferred from other wards or ICUs ( $28.9 \%$ of the patient population) and most of the patients who required MV after cardiopulmonary resuscitation died. These patients also contribute to the high mortality rate in the present study. Also, many patients died during the first three days after admission to the ICU, and refusal to admit such patients is not possible, according to hospital policy. For these reasons, there is a controversy regarding ICU admission of very elderly patients who have a very high mortality rate. Other studies reported much lower mortality rates for very elderly patients $(14.6-56 \%) .{ }^{10}$ These studies suggest that the severity of comorbidities rather than age is associated with the rate of mortality; proper management and treatment may improve outcomes. ${ }^{15}$ We suggest that patient characteristics, ICU type, ICU admission criteria, strategies for endof-life-care patients, and the experience of health-care personnel are important factors in terms of the rate of mortality.

It is well known that a long-term stay in ICU is associated with a higher mortality rate and a poor outcome. ${ }^{16}$ However, in this study, most of the nonsurvivors had a shorter LOS (4 days), and the mortality rate was higher in patients with a shorter LOS. Including postresuscitation, critical patients probably contributed substantially to this finding.

Several studies suggested that the need for MV is more common in elderly patients, and MV is associated with a worse prognosis. ${ }^{8}$ In this study, one-third of the patients were intubated, and most of these patients died in the ICU. The proportion of patients on MV (82.6\%), mean duration of MV (12.8 \pm 27 days), and mortality rate of these patients $(95.6 \%)$ are higher than that reported in previous studies. ${ }^{5}$ These negative outcomes may be due to the inclusion of patients with comorbidities in this study. The rate of noninvasive MV use is low in our country. This may be attributable to the abundance of critical patients requiring MV. It has been postulated that mortality in the very elderly ICU patients may be reduced by using noninvasive MV instead of MV. ${ }^{17}$

In this study, nonsurvivors had significantly lower albumin levels compared to survivors, but hypoalbuminemia did not have an independent association with mortality. An increased lactate level is associated with insufficient tissue perfusion and a high mortality rate. ${ }^{18}$ However, lactate clearance has been reported to have a limited value in predicting in-hospital mortality. ${ }^{18}$ In this study, lactate levels were higher in nonsurvivors than in survivors, but lactate levels did not have an independent association with mortality.

Another predictor of mortality for ICU patients is the APACHE II score, which is used worldwide for this indication. The index patient is evaluated during the first 24 hours of admission to ICU, and the worst values for each physiological variable within this period are considered. ${ }^{19}$ In a previous study, ${ }^{8}$ it was reported that high APACHE II scores on admission were associated with mortality in very old ICU patients. In another study, ${ }^{4}$ a high APACHE II score was the only independent predictor of mortality in very elderly ICU patients. In the present study, APACHE II score was one of the factors associated with mortality.

Some studies suggested that a tracheostomy improved patient's comfort and ventilation and helped these patients in weaning from MV. ${ }^{20}$ In this study, patients who underwent a tracheostomy had significantly longer LOS than those who did not undergo this procedure. We generally perform a tracheostomy after the tenth day of MV in our ICU, and one study suggested that performing a tracheostomy early shortens the duration of MV and LOS and is associated with a lower rate of mortality. ${ }^{21}$ On the contrary, another study suggested that performing a tracheostomy was associated with worse outcomes. ${ }^{20}$

Most of the elderly ICU patients undergo advanced life-support care, such as positive inotropic support, MV, and renal replacement therapies. ${ }^{15}$ In this study, the highest mortality rate occurred in patients with CKD, as was reported in other studies. ${ }^{10,15}$ The need for positive inotropic support is common in patients at high risk for mortality. ${ }^{10,15}$ Use of positive inotropic support was likely significantly associated with mortality in the present study.

In the present study, blood transfusion did not seem to reduce mortality, and it was associated with a longer LOS. Previous studies reported that blood transfusion is associated with an increased risk of infections and death and a longer LOS. ${ }^{22}$ On the contrary, a restrictive blood transfusion strategy is generally recommended for ICU patients. ${ }^{22}$

The present study had some limitations. Firstly, it was a single-center study. Local factors, such as ICU type and admission protocols, might have influenced our study results. Secondly, it was a retrospective study; thus, it was not possible to get access to functional capacity measures, such as the frailty index. This should be kept in mind when planning similar studies. Thirdly, the follow-up period of the study was short, and studies with longer follow-up data may provide more clinically relevant information. Fourthly, we evaluated only in-ICU mortality and did not have data about death after discharge from ICU. On the contrary, one strong point of the study was the fact that we admitted medical and surgical patients with various types of comorbidities.

In conclusion, we suggest that APACHE II score, need for MV, CKD, $C A D$, and need for inotropic support were independently associated with mortality in very elderly patients in ICUs. On the contrary, a tracheostomy and a blood transfusion seemed to be inversely associated with mortality. Notably, the rate of mortality was high, and most deaths occurred in the first three days after admission to ICU. We think that acknowledgment of the factors that have negative effects on clinical outcomes may aid while determining the admission of very elderly patients to ICUs. These patients, who are estimated to have a short survival and poor response to advanced treatment options, seem to have a substantial effect on ICU capacity. As a result, some of these patients might be admitted to end-of-lifecare units instead of ICUs to better use the limited capacity of ICUs.

\section{Author Contributions}

O.H.M. contributed to conceptualization, funding acquisition, methodology, and supervision; and O.H.M. and M.O. contributed to 
data curation, investigation, project administration, writing original draft, and writing, reviewing, and editing.

\section{ORCID}

Ökkeş H Miniksar (1) https://orcid.org/0000-0001-5645-7729

Mikail Özdemir @ https://orcid.org/0000-0001-7567-1763

\section{References}

1. World Population Prospects. Population division of the department of economic and social affairs of the United Nations Secretariat, the 2019 Revision. Available at: https://population.un.org/wpp/

2. Elderly Statistics. 2018. Available at: http://www.tuik.gov.tr/ PreHaberBultenleri.doid $=16057$

3. Lee SH, Lee TW, Ju S, Yoo JW, Lee SJ, Cho YJ, et al. Outcomes of very elderly ( $\geq 80$ years) critical-ill patients in a medical intensive care unit of a tertiary hospital in Korea. Korean J Intern Med 2017;32(4):675-681. DOI: 10.3904/kjim.2015.331.

4. Boumendil A, Somme D, Garrouste-Orgeas M, Guidet B. Should elderly patients be admitted to the intensive care unit? Intensive Care Med 2007;33(7):1252-1262. DOI: 10.1007/s00134-007-0621-3.

5. Nguyen $Y-L$, Angus DC, Boumendil A, Guidet $B$. The challenge of admitting the very elderly to intensive care. Ann Intensive Care 2011;1(1):29. DOI: 10.1186/2110-5820-1-29.

6. Bagshaw SM, Webb SAR, Delaney A, George C, Pilcher D, Hart GK, et al. Very old patients admitted to intensive care in Australia and New Zealand: a multi-centre cohort analysis. Crit Care 2009;13(2):R45. DOI: $10.1186 /$ cc7768.

7. Ihra GC, Lehberger J, Hochrieser H, Bauer P, Schmutz R, Metnitz B, et al. Development of demographics and outcome of very old critically ill patients admitted to intensive care units. Intensive Care Med 2012;38(4):620-626. DOI: 10.1007/s00134-012-2474-7.

8. Rellos K, Falagas ME, Sermaides G, Michalopoulos A. Sermaides G, Michalopoulos A. Outcome of critically ill oldest-old patients (aged 90 and older) admitted to the intensive care unit. J Am Geriatr Soc 2006;54(1):110-114. DOI: 10.1111/j.1532-5415.2005.00544.x.

9. Doğan Baki E, Yüksek A, Bezen BA, Saritaş TB, Sivaci R. Retrospective analysis of anesthesia in geriatric patients during endoscopic retrograde cholangiopancreatography abstract. Turk Geriatr Derg 2018;21(2):225-230. DOI: 10.31086/tjgeri.2018240423.

10. Fuchs L, Chronaki CE, Park S, Novack V, Baumfeld Y, Scott D, et al. ICU admission characteristics and mortality rates among elderly and very elderly patients. Intensive Care Med 2012;38(10): 1654-1661. DOI: 10.1007/s00134-012-2629-6.

11. Al-Dorzi HM, Tamim HM, Mundekkadan S, Sohail MR, Arabi YM, Ruokonen E, et al. Characteristics, management and outcomes of critically ill patients who are 80 years and older: a retrospective comparative cohort study. BMC Anesthesiol 2014;14(1):1-9. DOI: 10.1186/1471-2253-14-126.

12. Reinikainen $M$, Niskanen $M$, Uusaro $A$, Ruokonen $E$. Impact of gender on treatment and outcome of ICU patients. Acta Anaesthesiol Scand 2005;49(7):984-990. DOI: 10.1111/j.1399-6576.2005.00759.x.

13. Akın S, Gündoğan K, Coşkun R, Yüksel RC, Topaloğlu US, Öztürk F, et al. Critically ill elderly patient mortality: Is age a risk factor? J Med Surg Intensive Care Med 2014;5(2):26-9. DOI: 10.5152/dcbybd.2014.667.

14. Becker S, Müller J, de Heer G, Braune S, Fuhrmann V, Kluge S. Clinical characteristics and outcome of very elderly patients $\geq 90$ years in intensive care: a retrospective observational study. Ann Intensive Care 2015;5(1):53. DOI: 10.1186/s13613-015-0097-1.

15. De Rooij SE, Abu-Hanna A, Levi M. Factors that predict outcome of intensive care treatment in very elderly patients: a review Crit Care 2005;9(4):307-314. DOI: 10.1186/cc3536.

16. Toh HJ, Lim ZY, Yap P, Tang T. Factors associated with prolonged length of stay in older patients. Singapore Med J 2017;58(3):134-138. DOI: 10.11622/smedj.2016158.

17. Nava S, Grassi M, Fanfulla F, Domenighetti G, Carlucci A, Perren $A$, et al. Non-invasive ventilation in elderly patients with acute hypercapnic respiratory failure: a randomised controlled trial. Age Ageing 2011;40(4):444-450. DOI: 10.1093/ageing/afr003.

18. Ferreruela M, Raurich JM, Ayestarán I, Llompart-Pou JA. Hyperlactatemia in ICU patients: Incidence, causes and associated mortality. J Crit Care 2017;42:200-205. DOI: 10.1016/j.jcrc.2017.07.039.

19. Rordorf G, Koroshetz W, Efird JT, Cramer SC. Predictors of mortality in stroke patients admitted to an intensive care unit. Crit Care Med 2000;28(5):1301-1305. DOI: 10.1097/00003246-200005000-00007.

20. Baskin JZ, Panagopoulos G, Parks C, Rothstein S, Komisar A. Clinical outcomes for the elderly patient receiving a tracheotomy. Head Neck 2004;26(1):71-76. DOI: 10.1002/hed.10356.

21. Hosokawa K, Nishimura M, Egi M, Vincent JL. Timing of tracheotomy in ICU patients: a systematic review of randomized controlled trials. Crit Care 2015;19(1):424. DOI: 10.1186/s13054-015-1138-8.

22. Marik PE, Corwin HL. Efficacy of red blood cell transfusion in the critically ill: a systematic review of the literature. Crit Care Med 2008;36(9):2667-2674. DOI: 10.1097/CCM.0b013e3181844677. 